\title{
Stress level and self-concept among type 2 diabetes mellitus patients in Indonesia
}

\author{
RINA AMELIA ${ }^{1, \text { A, c-F }}$, DG KU NUR SYAHRINA-BINTI SAHBUDIN¹, A, B, E-G, ZULHAM YAMAMOTO², D-F \\ ORCID ID: 0000-0002-0419-9622 \\ ORCIDID: 0000-0002-8773-807X
}

${ }^{1}$ Faculty of Medicine, Universitas Sumatera Utara, Medan, Indonesia

${ }^{2}$ Department of Histology, Faculty of Medicine, Universitas Sumatera Utara, Medan, Indonesia

A - Study Design, B - Data Collection, C - Statistical Analysis, D - Data Interpretation, E - Manuscript Preparation, F - Literature Search, G - Funds Collection

Summary Background. Diabetes mellitus has several complications related to mental health, such as stress and depression. Stress may disrupt the self-concept of a person with type 2 diabetes mellitus (T2DM).

Objectives. The aim of this study was to analyze the relationship between stress and self-concept among T2DM patients in Medan, Indonesia.

Material and methods. This is a cross-sectional study of a total of 100 subjects. The subjects were selected using convenience sampling. The primary data were collected from interviews using questionnaire guidelines. The Perceived Stress Scale-10 was used to determine the stress level, while the Tennesse Self-Concept Scale was used to determine the patient's self-concept. The data were processed using SPSS and analyzed with the chi-squared test.

Results. The results showed that $83 \%$ of diabetic patients experienced a moderate level of stress, whereas $61 \%$ of patients had a fair self-concept. Furthermore, the chi-squared test showed that there was no relationship between stress and self-concept in T2DM patients $(p<0.05)$.

Conclusions. There was no relationship between stress level and self-concept among T2DM patients $(p<0.05)$. Although stress and self-concept are closely related, especially in T2DM patients, the present study did not find a relationship between the two variables. However, efforts should still be made to prevent mental health disorders and to control the disease. Key words: diabetes mellitus type 2, patients, surveys and questionnaires.

Amelia R, Syahrina-Binti Sahbudin DKN, Yamamoto Z. Stress level and self-concept among type 2 diabetes mellitus patients in Indonesia. Fam Med Prim Care Rev 2020; 22(2): 111-115, doi: https://doi.org/10.5114/fmpcr.2020.95313.

\section{Background}

Diabetes mellitus (DM) is a chronic illness whose prevalence has increased in the last few decades [1]. It is caused by insufficient insulin or insensitivity to insulin in the body, which can lead to an increase in blood glucose level in the body, known as hyperglycemia [2]. One of the main risk factors for DM is an unhealthy lifestyle leading to obesity, which is currently on the rise. Obesity increases the risk of type 2 diabetes (T2DM) and has doubled its prevalence from 1980 to 2014, with an increase of 422 million people [1]. Indonesia is third on the list of countries in the Western Pacific with the most DM cases, and it is predicted that 14.6-18.2 million people will suffer from DM by 2045 in the country [3]. About $1.8 \%$ of the population, or 160,913 people, in North Sumatra - a province of Indonesia - were diagnosed for DM, and approximately 788 people suffered from T2DM in 2013 [4, 5].

Categorized as a chronic disease, DM requires treatment throughout the life of the patient. This condition has a negative impact on the physical and psychological condition of the patient. The psychological effects that often occur in people with DM are depression, anxiety, and stress [6]. Among these psychological effects, stress is the one which is most often experienced by DM patients. Previous studies have reported that $50.7 \%$ of DM patients suffer from stress [6]. Stress leads to uncontrolled blood sugar levels in DM patients. When a person suffers from stress, it can trigger various hormones in the body that can affect blood sugar levels and $\mathrm{HbA}_{1,}$ directly or indirectly [7].

The stress experienced by DM patients due to their dependence on the life-sustaining therapy affects their self-belief and self-concept. The more stress felt by these patients, the higher the tendency to have a lower self-concept. Self-concept is a person's self-image, which involves all appearances of perception, values, and self-confidence that influence a person's behavior. Adaptability to the burden of chronic diseases such as DM affects self-concept [8]. A negative self-concept makes a patient feel stressed physically and psychologically with the situation. Some of the adverse effects that appear physically, such as a decreased immune system, slow down the wound healing process [9].

Furthermore, there is a relationship between the disease's chronicity and the patient's self-concept [10], and there is a relationship between self-concept and the incidence of depression in patients. Chronic diseases will interfere with the ability of patients to perform daily activities, so it can affect their self-esteem [11]. Low self-esteem will cause the patient to feel more depressed and to withdraw from other people. Low selfesteem can also lead to depression, anxiety, or prolonged anxiety, which will eventually make the patient feel stressed physically and psychologically. The psychological conditions, such as stress and depression, can aggravate the condition of DM patients because there is a significant relationship between stress and higher blood sugar levels.

The higher the stress level experienced by a patient, the lower the patient's self-concept. There is a significant relationship between the occurrence of stress in T2DM patients with the increased blood sugar level which then may disrupts their self-concept [12].

This supports the idea that DM patients should receive special attention from people around them so that they are not exposed to stressors. Family support is also important for DM patients, and it becomes a benchmark for success in their glycemic control [13]. This will eventually determine the quality of life for future DM patients [14]. 


\section{Objectives}

The aim of this study was to analyze the association between stress and self-concept among T2DM patients in Medan, Indonesia.

\section{Material and methods}

\section{Study design and participants}

This cross-sectional study was carried out at a Diabetes Clinic in Medan, a province of North Sumatera, Indonesia, which provides DM outpatient care. The study population was T2DM patients who sought medical treatment and advice at the clinic. A total of 100 subjects were recruited for this study using the convenience sampling method. The inclusion criteria were patients who had been suffering for DM for one year, patients who came independently, and individuals who communicate well. The exclusion criteria were patients who had a history of psychiatric problems (stress, depression, or other mental problems) before suffering from T2DM (as shown in medical records and interviews), patients who had attempted suicide, and patients with severe complications who always depend on other people.

\section{Measures}

The subjects were interviewed using questionnaires of stress and self-concept. The stress level was determined with the Perceived Stress Scale, with a total of 10 questions based on the stress level of the patients one month prior to assessment. Each answer was given a score, and the stress level was classified into three categories based on the total score: 0-13 points $=$ mild stress, $14-26$ points $=$ moderate stress, and $27-40$ points $=$ severe stress. Self-concept was determined using the Tennessee Self-Concept Scale questionnaire with a total of 20 questions covering five components, four questions representing each component. Each answer was scored, and the total score was categorized into three levels of self-concept, based on the mean and standard deviation values and according to the instructions of the instrument: good $=y \geq x+\mathrm{SD}$, fair $=y$ $\geq x+\mathrm{SD} \leq y$, or poor $=y<x-\mathrm{SD})$. The two questionnaires had Alpha Cronbach values of 0.87 and 0.884 , respectively. The data were analyzed using the chi-squared test in the SPSS computer program. The confidence interval was $95 \%$, and a $p$-value of $<0.05$ was considered statistically significant.

\section{Ethical consideration}

An opinion from the Ethics Committee was not required to perform the study.

\section{Results}

The majority of the patients in this study (40\%) were 46-55 years old (early elderly); $50 \%$ of them were men and $50 \%$ women (Table 1). The highest percentage of ethnic groups in the patients was Javanese, with 24 people (24\%). The most common educational level of the patients was bachelor's degree, with 47 people (47\%); 58 patients (58\%) had an entrepreneurial job. In terms of the length of DM disease, half of the subjects (52\%) had had DM for 5-10 years. Approximately half of the subjects $(49 \%)$ did not have a family history of DM. Moderate stress levels were experienced by 83 subjects (83\%), whereas 61 patients had a fair self-concept.

Several risk factors are present in T2DM, such as age, gender, education level, duration of DM, and family history (Table 2). The duration of DM disease had an impact on the occurrence of stress in T2DM patients $(p<0.05)$. The level of education influenced the self-concept of T2DM patients. A higher level of education resulted in a better self-concept $(p<0.05)$.

\begin{tabular}{|l|l|l|}
\hline \multicolumn{3}{|l|}{ Table 1. Characteristics of the study subjects } \\
\hline Characteristics & Frequency $(\boldsymbol{n})$ & Percentage (\%) \\
\hline Age & & \\
25-35 years old & 1 & 1 \\
36-45 years old & 5 & 5 \\
46-55 years old & 40 & 40 \\
56-65 years old & 37 & 37 \\
> 65 years old & 17 & 17 \\
\hline Gender & & \\
Men & 50 & 50 \\
Women & 50 & 50 \\
\hline Education & & \\
Kindergarten & 4 & 4 \\
Junior High & 8 & 8 \\
High School & 24 & 24 \\
Diploma & 11 & 11 \\
Bachelor's degree & 47 & 47 \\
Master's degree & 4 & 4 \\
Other & 1 & 1 \\
None & 1 & 1 \\
\hline Duration of disease & & \\
< 5 years & 42 & 42 \\
5-10 years & 52 & 52 \\
>10 years & 6 & 6 \\
\hline Family history & & \\
Father only & 26 & 26 \\
Mother only & 25 & 25 \\
None & 49 & 49 \\
Both & 0 & 0 \\
\hline Stress & 8 & 83 \\
Mild & 83 & 22 \\
Moderate & 9 & \\
Severe & 17 & \\
\hline Self-concept & 22 & \\
Poor & Fair & \\
Good & & \\
\hline
\end{tabular}

Table 2. Factors affecting stress level in type $\mathbf{2}$ diabetes mellitus patients

\begin{tabular}{|l|l|l|l|l|}
\hline \multirow{2}{*}{ Characteristics } & \multicolumn{2}{|l|}{ Stress Level } & \multirow{2}{*}{$p$} \\
\cline { 2 - 4 } & mild & moderate & severe & \\
\hline Age & & & & \\
25-35 years old & $0(0)$ & $1(100)$ & $0(0)$ & \\
46-55 years old & $0(0)$ & $4(80)$ & $1(20)$ & \\
56-65 years old & $3(7.5)$ & $33(82.5)$ & $4(10)$ & 0.964 \\
$>$ 65 years old & $3(8.1)$ & $32(86.5)$ & $2(5.4)$ & \\
\hline Gender & $2(11.8)$ & $13(76.5)$ & $2(11.8)$ & \\
Men & & & & \\
Women & $4(8.0)$ & $42(84.0)$ & $4(8.0)$ & \multirow{2}{*}{0.940} \\
\hline Education & $4(8.0)$ & $41(82.0)$ & $5(10)$ & \\
Kindergarten & $2(50)$ & $2(50)$ & $0(0)$ & \\
Junior High & $1(12.5)$ & $6(75.0)$ & $1(12.5)$ & \\
High School & $2(8.3)$ & $19(79.2)$ & $3(12.5)$ & \\
Diploma & $0(0)$ & $11(100)$ & $0(0)$ & \multirow{2}{*}{0.433} \\
Bachelor & $3(6.4)$ & $39(83.0)$ & $5(10.6)$ & \\
Master & $0(0)$ & $4(100)$ & $0(0)$ & \\
Other & $0(0)$ & $1(100)$ & $0(0)$ & \\
None & $0(0)$ & $1(100)$ & $0(0)$ & \\
\hline Duration of & & & & \\
disease & & & & \\
< 5 years & $1(2.4)$ & $36(85.7)$ & $5(11.9)$ & \multirow{2}{*}{0.023} \\
5-10 years & $7(13.5)$ & $42(80.0)$ & $3(5.8)$ & \\
> 10 years & $0(0)$ & $5(83.3)$ & $1(16.7)$ & \\
\hline Family history & & & & \\
Father only & $3(11.5)$ & $21(80.8)$ & $2(7.7)$ & \\
Mother only & $2(8.0)$ & $22(88.0)$ & $1(4.0)$ & 0.789 \\
None & $3(6.1)$ & $40(81.6)$ & $6(12.2)$ & \\
Both & $0(0)$ & $0(0)$ & $0(0)$ & \\
\hline
\end{tabular}


A total of $83 \%$ of subjects reported experiencing moderate stress, while nine subjects (9\%) experienced severe stress; the majority of the subjects had a fair self-concept (61\%; Table 3 ). Out of the eight subjects who experienced mild stress, five had a fair self-concept. Similarly, 51 of the 83 subjects with moderate stress levels had a fair self-concept (51\%), while 5 of the 9 subjects who experienced severe stress had a fair self-concept (5\%). The chi-squared test was carried out to analyze the relationship between the stress level and the self-concept of type 2 DM patients. The analysis returned a $p$-value of $0.70(>0.05)$, which means that there was no relationship between stress and self-concept in T2DM patients at the Diabetes Clinic.

\begin{tabular}{|l|l|l|l|l|}
\hline \multicolumn{5}{|l|}{ Table 3. Factors influencing self-concept of type 2 DM patients } \\
\hline \multirow{2}{*}{ Characteristics } & \multicolumn{3}{|l|}{ Self-Concept } & $p$ \\
\cline { 2 - 5 } & poor & fair & good & \\
\hline Age & & & & \\
25-35 years old & $0(0)$ & $1(100)$ & $0(0)$ & \\
36-45 years old & $1(20)$ & $3(60)$ & $1(20)$ & \\
46-55 years old & $3(7.5)$ & $23(57.5)$ & $14(35.0)$ & 0.158 \\
56-65 years old & $7(18.9)$ & $25(67.6)$ & $5(13.5)$ & \\
>65 years old & $6(35.3)$ & $9(52.9)$ & $2(11.8)$ & \\
\hline Gender & & & & \\
$\quad$ Men & $9(180$ & $29(58)$ & $12(24)$ & 0.824 \\
Women & $8(16)$ & $32(64)$ & $10(20)$ & \\
\hline Education & & & & \\
Kindergarten & $0(0)$ & $3(75.0)$ & $1(25.0)$ & \\
Junior high & $1(12.5)$ & $6(75.0)$ & $1(12.5)$ & \\
High School & $9(37.5)$ & $13(54.2)$ & $2(8.3)$ & \\
Diploma & $2(18.2)$ & $6(54.4)$ & $3(27.3)$ & 0.017 \\
Bachelor's degree & $5(10.6)$ & $31(66.0)$ & $11(23.4)$ & \\
Master's degree & $0(0)$ & $1(25.0)$ & $3(75.0)$ & \\
Other & $0(0)$ & $0(0)$ & $1(100)$ & \\
None & $0(0)$ & $1(100)$ & $0(0)$ & \\
\hline Duration of disease & & & & \\
< 5 years & $6(14.3)$ & $29(69.0)$ & $7(16.7)$ & 0.264 \\
5-10 years & $11(21.2)$ & $29(55.0)$ & $12(23.1)$ & \\
> 10 years & $0(0)$ & $3(50.0)$ & $3(50)$ & \\
\hline Family history & & & & \\
Father only & $4(15.4)$ & $15(57.7)$ & $7(26.9)$ & \\
Mother only & $6(24.0)$ & $14(56.0)$ & $5(20.0)$ & 0.798 \\
None & $7(14.3)$ & $32(65.3)$ & $10(20.4)$ & \\
Both & $0(0)$ & $0(0)$ & $0(0)$ & \\
\hline
\end{tabular}

\begin{tabular}{|c|c|c|c|c|c|}
\hline \multirow[t]{2}{*}{ Stress Level } & \multicolumn{3}{|c|}{ Self-concept } & \multirow[t]{2}{*}{ Total } & \multirow[t]{2}{*}{$p$} \\
\hline & good & fair & poor & & \\
\hline Mild & $2(2)$ & $5(5)$ & $1(1)$ & $8(8)$ & \multirow[t]{3}{*}{0.70} \\
\hline Moderate & 19 (19) & $51(51)$ & $13(13)$ & $83(83)$ & \\
\hline Severe & $1(1)$ & $5(5)$ & $3(3)$ & $9(9)$ & \\
\hline
\end{tabular}

\section{Discussion}

Stress is a form of mental disorder that is often experienced with depression and anxiety [6]. Diabetes-related stress in T2DM patients occurs due to disturbances in people's emotions because they feel that their actions and activities must be limited or controlled [15]. These changes will lead to more stress because they find it difficult to change their lifestyle and abide by the therapy [16]. Modifications by DM patients must be done immediately so that the DM is well-controlled and that further complications are prevented. This condition will be a prolonged stressor. The continuous stress and lack of resolution lead to irregular eating, low self-efficacy, and poor diet and exercise patterns, which ultimately result in poor glycemic control $[17,18]$.
The results of the present study indicate that the majority of subjects experienced a moderate level of stress (83\%). In contrast, a previous study found the prevalence of stress and depression in T2DM patients to be lower, at $49.2 \%$ and $41.7 \%$, respectively [10]. Furthermore, other studies have reported that patients with chronic diseases were at risk of suffering from mental disorders such as stress, depression, and anxiety [18]. Their risk of experiencing mental disorders was $25-33 \%$ higher compared to those who did not suffer from chronic diseases [19]. Stress experienced by chronic patients has a negative impact on their health, especially in T2DM patients, because they will experience chronic stress throughout their lives [20]. Emotional stress as a result of anxiety and burden characterized by frustration may overwhelm the patient; thus, the longer a person has diabetes, the more that person is at risk of chronic stress [16]. Several studies have found that various factors can cause stress in DM patients, including gender, duration of diabetes, $\mathrm{HbA}_{1 \mathrm{c}}$ levels, family history of stress, life events, and alcohol use $[10,21]$.

The results of the present study indicate that the duration of DM had an effect on the incidence of stress and the severity of stress in DM patients. About 42 people (80\%) experienced a moderate level of stress after 5-10 years of illness. A longer duration of DM can also affect the level of stress in DM patients because of the longer pain and discomfort. Stress experienced by DM patients is preventable by providing proper education and positive support from the family and people around the patients to help them accept the changes and adapt to their disease $[22,23]$. Patients who receive social or familial support, especially couples, are able to maintain their mental and emotional condition, so they can avoid stress and have a better quality of life [23].

Adequate knowledge and a good understanding of the disease will be beneficial for the patients because it can reduce the stress in dealing with the disease. The more education a patient has about the illness, the less stress the patient will experience [24]. Adequate knowledge will help patients to control their blood sugar levels, so they can prevent the occurrence of complications and have a better quality of life. Providing education in the form of Diabetes Self-Management Education and Support has an effect on stress reduction in T2DM patients [24].

The present study also shows that approximately $61 \%$ of patients have a fair self-concept. This is different from other studies, which found that $53.3 \%$ of patients had a poor self-concept [25]. Previous studies indicated factors that can influence one's self-concept, such as education, media, appearance, culture, abuse, relationships, gender, income, and age. One's level of education can affect one's self-concept. People with a higher level of education will have better thinking ability and self-confidence. Most of the DM patients in this study had a university education, which indirectly led to a positive impression on the self-concept questionnaire. Therefore, even though they have T2DM, they can maintain a good self-concept. A higher education level can help the patients to understand more about their disease, so it can indirectly prevent them from experiencing severe stress. In other words, the higher the education level of the patients, the better their understanding of their condition [26].

Self-concept is self-image, and it involves all perceptions, appearances, values, and self-perception beliefs that influence behavior. There are four components of self-concept: personal identity, body image, role performance, and self-esteem [6]. The concept of positive self is crucial for one's mental and physical health. Individuals with positive self-concepts are better at developing and maintaining interpersonal relationships and withstanding psychological and physical illness.

The analysis from the chi-squared test revealed that there was no relationship between stress and self-concept in T2DM patients. This may be because the self-concept of DM patients was generally better even though they experienced stress due to DM; therefore, the stress that they experienced did not have 
much effect on their self-concept. The concepts of self-esteem and quality of life are interrelated in that the higher the self-esteem, the better the quality of life in DM patients [2]. Stress due to chronic disease can significantly reduce one's self-esteem and self-concept $[6,27]$. Self-concept is the root of all behaviors shown to people [10]. People with a positive self-concept can be more developed, and interpersonal relationships can protect against disease and provide resistance to physical and mental illness. A person who has a positive self-concept is stronger and better at accepting the changes that occur throughout life [6]. DM patients would experience various stresses that lead to potential loss and lifestyle changes. Subjective symptoms and medical complications can result in functional limitations and changes in quality of life [3]

The other factors that the DM patients with a fair self-concept had were a good family atmosphere and the right approach from medical personnel to patients and their families. The patients who come to the Diabetes Clinic have been treated there for years, so there is a good relationship between patients and families or patients and the nurses, doctors, and clinic staff members. Periodically, joint gymnastics education and activities are conducted to increase the patient's understanding of the disease and support the patient's independent behavior towards the disease. Support provided by healthcare workers will help patients to understand their disease better, accept their conditions, and undergo DM therapy effectively $[8,22,25]$. Healthcare services at the clinic that provide holistic support for the treatment of T2DM are adequate in reducing the stress of patients who seek treatment at the clinic. Despite the results of this study, it cannot be stated that there is no relationship be- tween stress and self-concept in T2DM patients. Previous studies have demonstrated that complications such as peripheral neuropathy and DM retinopathy caused changes in the physical characteristics and abilities of patients, which triggered stress in them [21]. This stressful event can decrease their self-esteem and self-value, which also affects the patient's self-concept [26]. Self-acceptance of DM patients is strongly influenced by the level of stress that they experience [27]. Therefore, a person who has a great coping mechanism tends to have a higher and better self-concept $[8,19]$.

\section{Conclusions}

Although stress and self-concept are closely related, especially in DM patients, the study did not find a relationship between the two variables. However, efforts should still be made to prevent mental health disorders and to control the disease. It is essential for family doctors, especially those who work in primary healthcare, to perform stress screening in T2DM patients regularly so that the stress can be diagnosed and treated immediately. Family doctors should also involve the patient's family in providing support and motivation so that the patient undergoes treatment with more confidence and a better self-concept. As a result, DM patients can control their condition well and have a better quality of life.

Acknowledgments. The authors would like to thank the Universitas Sumatera Utara for supporting this study through the TALENTA research grant.

Source of funding: This work was funded from the Universitas Sumatera Utara by supporting this study through the TALENTA research grant, reference number 4167/UN5.1.3.1/PPM/2019.

Conflicts of interest: The authors declare no conflicts of interest.

\section{References}

1. Roglic G. WHO Global report on diabetes: a summary. IJNCD 2016; 1(1): 3-8.

2. The Indonesian Ministry of Health. Basic Health Research (Riskesdas) Health Research and Development Agency [online data] 2013 [cited 10.07.2019]. Available from URL: https://www.kemkes.go.id/resources/download/pusdatin/infodatin/infodatin-diabetes.pdf.

3. Ansong K. The management of type 2 diabetes mellitus: compliance, barriers and effect on glycemic control of adult outpatients in Sunyani Municipality, Brong Ahafo Region-Ghana [Doctoral dissertation]. Kumasi (Ghana): Kwame Nkrumah University of Science and Technology; 2018.

4. Kementerian Kesehatan RI. Riset Kesehatan Dasar (Riskesdas) Badan Penelitian dan Pengembangan Kesehatan. 2013 [cited 10.07.2019]. Available from URL: https://s3.amazonaws.com/academia.edu.documents/54892363/Riskesdas_baru.pdf? (in Indonesian).

5. Medan City Health Office. Medan City Health Profile 2016 [cited 10.07.2019]. Available from URL: http://ppid.pemkomedan.go.id/.

6. Tan KC, Chan GC, Eric H, et al. Depression, anxiety and stress among patients with diabetes in primary care: a cross-sectional study. Malays Fam Physician 2015; 10(2): 9-21.

7. Derek MI, Rottie JV, Kallo V. Relationship between stress levels and blood sugar level in type 2 diabetes mellitus patients at Pancaran Kasih Hospital, GMIM Manado. eNursing Journal 2017; 5(1): 1-6.

8. Samadi N, Safavi M, Mahmoodi M. Impact of quality of life education on self-concept among type 2 diabetes patients. J Diabetes Metab 2011; 2(5): 1-5.

9. Pourhaji F, Delshad MH, Ammari AA, et al. Foot-care self-efficacy beliefs, physical self-concept and actual foot-care behavior in people with diabetes mellitus. IJMPP 2016; 1(3): 101-107.

10. Chew BH, Vos R, Mohd-Sidik S, et al. Diabetes-related distress, depression and distress-depression among adults with type 2 diabetes mellitus in Malaysia. PloS ONE 2016; 11(3): e0152095.

11. Luyckx K, Rassart J, Aujoulat I, et al. Self-esteem and illness self-concept in emerging adults with type 1 diabetes: long-term associations with problem areas in diabetes. JHP 2016; 21(4): 540-549.

12. Chouhan VL, Shalini V. Coping strategies for stress and adjustment among diabetics. JIAAP 2006; 32(2): 106-161.

13. Amelia R, Yunanda Y. Relationship between depression and glycemic control among patients with type 2 diabetes in Medan. IOP Conf Ser Earth Environ Sci 2018; 125(1): 012170.

14. Amelia R, Lelo $A$, Lindarto $D$, et al. Quality of life and glycemic profile of type 2 diabetes mellitus patients of Indonesian: a descriptive study. IOP Conf Ser Earth Environ Sci 2018; 125 (1): 012171.

15. Okwaraji FE, Onyebueke GC, Nduanya CU, et al. Gender differences, loneliness, self esteem and depression in a sample of Nigerian University students. JPPD 2017; 1(1): 26-37.

16. Fisher L, Glasgow RE, Strycker LA. The relationship between diabetes distress and diabetes depression with glycemic control among patients with type 2 diabetes. Diab Care 2010; 33: 1034-1036.

17. Rook KS, August KJ, Choi S, et al. Emotional reactivity to daily stress, spousal emotional support, and fasting blood glucose among patients with type 2 diabetes. JHP 2016; 21(11): 2538-2549.

18. Ivbijaro GO. Mental health and chronic physical illnesses: the need for continued and integrated care - World Mental Health Day 2010. MHFM 2010; 7(3): 127. 
19. Young-Hyman D, De Groot M, Hill-Briggs F, et al. Psychosocial care for people with diabetes: a position statement of the American Diabetes Association. Diab Care 2016; 39(12): 2126-2140.

20. Hilliard ME, Joyce P, Hessler D, et al. Stress and A1c among people with diabetes across the lifespan. Current Diab Reports 2016; 16(8): 67, doi: 10.1007/s11892-016-0761-3.

21. Kaur G, Tee GH, Ariaratnam S, et al. Depression, anxiety and stress symptoms among diabetics in Malaysia: a cross sectional study in an urban primary care setting. BMC Fam Pract 2013; 14(1): 69, doi: 10.1186/1471-2296-14-69.

22. Johnson MD, Anderson JR, Walker A, et al. Spousal overprotection is indirectly associated with poorer dietary adherence for patients with type 2 diabetes via diabetes distress when active engagement is low. BJHP 2015; 20(2): 360-373.

23. Amelia R, Wahyuni AS, Felicia RA. Relationship between family support with quality of life among type 2 diabetes mellitus patients at Amplas primary health care in Medan, Indonesia. IOP Conf Series Journal of Physics Conf Series 2018; 1116: 052004, doi:10.1088/1742$6596 / 1116 / 5 / 052004$.

24. Wiastuti SM, Rondhianto R, Widayati N. Effects of diabetes self-management education and support on stress in type 2 diabetes mellitus (dm) patients in Patrang Community Health Center at Jember Area (the effect of diabetes self-management education and support [DSME/S] on stress. Pustaka Kesehatan 2017; 5(2): 268-275.

25. Strandberg RB, Graue M, Wentzel-Larsen T, et al. Relationships of diabetes-specific emotional distress, depression, anxiety, and overall well-being with $\mathrm{HbA}_{1 c}$ in adult persons with type 1 diabetes. J Psychosom Res 2014; 77(3): 174-179.

26. Luyckx K, Rassart J, Weets I. Illness self-concept in type 1 diabetes: a cross-sectional view on clinical, demographic, and psychosocial correlates. Psychol Health Med 2015; 20(1): 77-86.

27. Salomé GM, Ferreira LM. Locus of health control, body image and self-image in diabetic individuals with ulcerated feet. J Nurs UFPE on line 11(9): 3419-3428.

Tables: 4

Figures: 0

References: 27

Received: 1.03 .2019

Reviewed: 17.03.2019

Accepted: 22.10.2019

Address for correspondence:

Rina Amelia, MD, PhD

Department of Community Medicine and Public Health

Faculty of Medicine

Universitas Sumatera Utara

Medan

Indonesia

Tel.: +62 8126444284

E-mail: drrinaamelia@gmail.com 